\title{
STRENGTH AND DUCTILITY IN REINFORCED CONCRETE FRAMES DESIGNED WITH MEXICAN CODES
}

\author{
M. Rodriguez*
}

\begin{abstract}
The strength and ductility capacities of several structural sections of members in typical reinforced concrete frames designed with Mexican codes are calculated using analytical models for confined concrete and reinforcing steel. These ductility capacities are associated with global displacement ductilities in the RC frames using approximate methods of analysis described in this paper. Results obtained in this investigation are correlated with typical pattern of structural damage in RC frames observed during the 1985 Mexico Earthquake. Some aspects of the seismic performance of fully ductile frames designed according to the 1987 Mexico City Building code are also discussed, as well as the effect of some mechanical properties of reinforcing steel on the strength and ductility of RC frames.
\end{abstract}

\section{INTRODUCTION}

Because of the random nature of earthquakes, the design forces specified by seismic codes can be largely underestimated during strong earthquakes, as was the case for both the 1985 Mexican and Chilean Earthquakes. The performance of structures during these earthquakes suggests that code designed structures have significant overstrengths which are not considered by seismic codes. Evidence of this overstrength in some structures or structural elements is documented in the literature $[1,2,19]$.

The seismic performance of structures cannot be defined in terms of strength only, but must also take into account additional parameters related to the inelastic response, such as the displacement ductility ratio and the hysteretic energy dissipation capacity. The study of building performance during the 1985 Mexico Earthquake suggests that collapse or severe structural damage were caused, among other factors, by inadequate capacities of these parameters. As a consequence, the 1987 Seismic Code provisions for Mexico City, RDF87 [3], is aimed at improving the ductility capacity of structures. Although it is qualitatively known that these capacities have been improved, insufficient efforts have been made to quantify these improvements.

Instituto de Ingenieria,

Universidad Nacional de Mexico,

Mexico.

Currently

Visiting Research Fellow,

Depertment of Civil Engineering,

University of Canterbury,

Christchurch, New Zealand.
It is also of interest to evaluate the strength and ductility capacities of Mexican code designed RC frames, and relate these capacities to the observed building performance during the 1985 Mexico Earthquake. Several methods for evaluating the strength and ductility demands of structures are available, however little effort has been made to relate these demands to the appropriate ductility capacities or to explain the sources of overstrength in structures,

The objectives of this paper are : 1) To evaluate and discuss the strength and ductility capacity of typical RC sections designed according to several Mexico City building codes and to relate these local ductilities to the global displacement ductility ratio of the structure; 2) To evaluate the implications of these analytical results in relation to the building performance observed during the 1985 Mexico Earthquake, and 3) To evaluate and discuss the soundness of the 1987 Mexico Seismic Code in improving the seismic performance of $R C$ frames compared with frames designed according to previous Mexican Seismic Codes.

This paper begins by establishing the global displacement ductility capacity in RC frames obtained using approximate methods of analysis. The strength and ductility capacities of several structural sections of members in typical frames of three buildings are then calculated using analytical models for confined concrete. The mechanical behaviour of the reinforcing steel is defined using data from a sample of reinforcing bars commonly used in Mexico. Finally, the implications of this investigation are discussed. 


\section{DUCTILITY DEMANDS IN REINFORCED CONCRETE} FRAMES

Time history nonlinear analysis of planar frames subjected to a specific ground motion is commonly used by researchers for evaluating the ductility demands of structures. This approach requires simplistic hypotheses that in some cases are not realistic. It is also evident that results from this type of analysis are only valid for the specific ground motion used in the analysis.

Because this approach involves a considerable amount of work, designers usually follow the approach proposed by several seismic codes. These allow the use of elastic analysis with elastic design forces reduced by a factor associated to the displacement ductility capacity of the structure. These factors are usually related to general characteristics of the structure, and because of the complexity of the problem these factors are mostly based on engineering judgement [1].

It is evident that for the evaluation of the displacement ductility capacity of a RC frame, the use of a simple analytical approach based on rational basic hypotheses appears attractive. An example of this type of approach is given by Park and Paulay [4], and is used in this investigation. This approach is based in studying two types of collapse mechanisms: column sidesway and beam sidesway mechanisms.

\section{DUCTILITY DEMANDS IN COLUMN SIDESWAY MECHANISM}

Figure la shows the column sidesway mechanism developing in the ith storey. A frame with $n$ stories, and an interstory height of $l_{c}$ is considered first. The lateral deflection at the top of the rth storey at first yield relative to the base of the structure, $\delta_{y}$ can be found using the methodology outlined by Park and Paulay [4]. This deflection is

$$
\delta_{y}=I_{c}^{2} / 6 \underset{\left.\phi_{c 2}(r-2 / 3)+\phi_{c 3}+\phi_{c 4}+\phi_{c 5}+\ldots+\phi_{c r}\right]}{\phi_{c}(2.25 r-1 / 2)+}
$$

where $\phi_{c i}$ is the curvature at the bottom of the ith storey column. It is assumed that the points of contraflexure occur at 0.81 from the bottom of the columns of the bottom storey, $0.6 I_{c}$ for the second storey, and $0.51_{c}$ for all other stories. These values differ from those used in the reference [4], and they are intended to represent typical values found in results of analysis of $R C$ frames designed according to Mexican Seismic codes. It can be shown that if points of contraflexure occur at mid-height in the columns, ductility demands would be larger than those using Equation (1).

The column ductility curvature factor, $\phi_{u c} / \phi_{y c i}$ for the column sidesway mechanism developed in the ith storey is given by [4]

$\phi_{\mathrm{uc}} / \phi_{\mathrm{yci}}=1+(\mu-1) \frac{\delta_{\mathrm{y}}}{\phi_{\mathrm{yci}} 1_{\mathrm{pc}}^{2}\left[1_{\mathrm{c}} / 1_{\mathrm{pc}}-1\right]}$

where $\phi_{u c}$ and $\phi_{y c i}$ are the ultimate and yield curvatures of the ith-storey column, $I_{\text {cc }}$ is the plastic hinge length, and $\mu$ is the displacement ductility factor. Combining Equations (1) and (2), and assuming the critical sections in columns reach first yield at the same time with a curvature equal to $\phi_{y c}$, we have

$\phi_{\mathrm{uc}} / \phi_{\mathrm{yc}}=1+[(\mu-1) / 6](4.25 \mathrm{r}-19 / 6) \frac{\left(1_{\mathrm{c}} / 1_{\mathrm{pc}}\right)^{2}}{\left(1_{\mathrm{c}} / 1_{\mathrm{pc}}-1\right)}(3)$

\section{DUCTILITY DEMANDS IN BEAM SIDESWAY MECHANISM}

The expression for $\mu$, in the top of the rthstorey in a beam sidesway mechanism (see Figure $1 b$ ) is given by [4]

$$
\mu=1+r I_{c} \frac{I_{b}}{1} \frac{\theta_{p b}}{\delta_{y}}
$$

$l$ and $I_{b}$ are the beam clear length and length between plastic hinges in the beam. The plastic rotation in beams, $\theta_{p b}$, is given by

$$
\theta_{\mathrm{pb}}=\left(\phi_{\mathrm{ub}}-\phi_{\mathrm{yb}}\right) 1_{\mathrm{pb}}
$$

$\phi_{\mathrm{ub}}$ and $\phi_{\mathrm{yb}}$ are the ultimate and yield curvature in the critical beam sections and $l_{\mathrm{pb}}$ is the plastic hinge length. Usually $\theta_{\mathrm{pb}}$ is governed by the negative plastic hinge [4], as was the case found in this investigation.

Assuming that the critical sections in

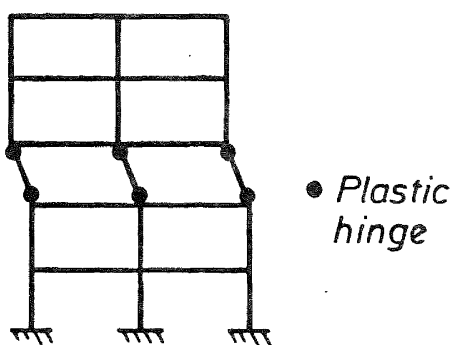

(a)

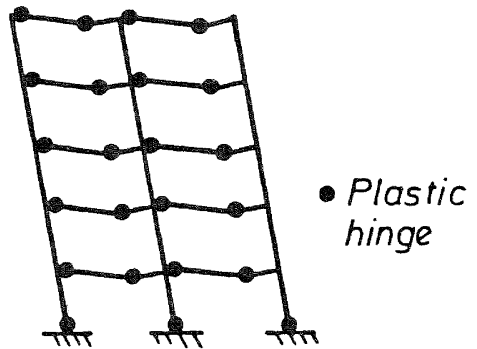

(b)

Figure 1 Typical collapse mechanisms in frames

a) Column sidesway mechanism

b) Beam sidesway mechanism 
columns have the same curvature $\phi_{c r}$ at the first yielding of the structure, and combining Equations (1), (4) and (5), we have:

$\phi_{\mathrm{ub}} / \phi_{y b}=1+\frac{\alpha}{6 r}(\mu-1)(4.25 r-19 / 6) \frac{1}{I_{b}} \frac{I_{c}}{I_{p b}}$

where

$$
\alpha=\phi_{\mathrm{cr}} / \phi_{\mathrm{yb}}
$$

The curvature ductility in the critical column sections for the sidesway beam mechanism can be obtained from a similar procedure to that followed to obtain Equation 6 , but working in terms of the plastic rotation in columns, $\theta_{p c}$, instead of $\theta_{p b}$, then

$\phi_{\mathrm{uc} 1} / \phi_{\mathrm{yc} 1}=1+\frac{(\mu-1)}{6 r} \frac{1_{c}}{1_{p c}}(4.25 r-19 / 6) \Omega$

where $\phi_{\mathrm{uc}}$ and $\phi_{\mathrm{yc}}$ are the ultimate curvature and yielding curvature respectively both calculated at the bases of the columns and where

$$
\Omega=\phi_{c r} / \phi_{y c 1}
$$

\section{DUCTILITY DEMANDS IN TYPICAL RC FRAMES}

An approximation to the average overall displacement ductility factor of a framed structure can be obtained by defining it as the displacement ductility factor at half the building height [4]; thus, we have

$$
r=0.5 \mathrm{n}
$$

Typical values of column plastic hinge length used in this investigation were $l_{p c}=0.5 \mathrm{~h}_{c}$ [2], where $h_{c}$ is the column section depth. other values, $1=5 \mathrm{~h}$ and $3 \mathrm{~h}$, were also used representing a typical range of values found in RC frames; these resulted in values of the $l_{c} / l_{p c}$ ratios equal to 10 and 6 respectively. $A$ typical value for the beam plastic hinge length was $l_{1}=2 / 3 h_{h}$ representing an approximation to results found by corley [5], where $h_{b}$ is the beam depth. The ratios $l_{b} / l=$ $3 / 4$ and $h_{b} / h_{c}=1$ were assumed; consequently, the $1_{c} / 1_{p b}$ ratios were 7.5 and 4.5 .

The values for $\alpha$ and $\Omega$ were both taken equal to 1. Equation 6 indicates that if higher values of $\alpha$ were used, curvature ductility demands would be higher. As is mentioned by Park and Paulay [4], this also shows the disadvantages of using RC frames with columns much more flexible than beams. The value assumed for $\Omega$ is reasonably on the conservative side.

The curvature ductility demands for beam sidesway mechanisms and column sidesway mechanisms, related to $\mu$ equal to 2 and 4 , were evaluated using Equations 3,6 and 8 , using the values of the parameters mentioned above. The results shown in Figures 2 to 4 indicate that curvature ductility demands in column bases for the beam sidesway mechanism are much smaller than those required for the column sidesway mechanism. This is in agreement with the approach generally used by seismic codes for avoiding column sidesway mechanism.

\section{MECHANICAL PROPERTIES OF REINFORCING STEEL MANUFACTURED IN MEXICO}

The steel stress-strain curve can be defined by five basic parameters: the yield strength, $f_{y}$, the ultimate strength, $f_{\text {su, }}$ the yield strain, $\epsilon_{y}$, the strain at the beginning of strain hardening, $\epsilon_{\text {sh, and the ultimate }}$ strain, $\epsilon_{\text {u }}$ (See Figure 5). There is not enough information on the statistical data for these parameters in Mexico. The data source used in this investigation was obtained at the Instituto de Ingenieria, Universidad Nacional de Mexico, from a sample of 20 deformed bars with different diameters including bars of $25 \mathrm{~mm}$. The lower and upper values for the five basic parameters found from these data were selected, and identified in this investigation as $A 1$ and $A 2$ steel respectively. These values are shown in Table 1 along with the minimum values specified by the Mexican standard [6], which are identified as corresponding to the A3 steel. In Table 1, it can be seen that the properties of $\mathrm{A} 1$ and $\mathrm{A} 3$ steel are similar, so only the $A 1$ and $A 2$ steel are considered in this investigation. The stress-strain curves were idealised considering both the values of Table 1 and the strain hardening curve proposed in the reference 4. The resulting stress-strain curves for $A 1$ and $A 2$ steel are shown in Figure 6 .

\section{DEFINITION OF AVAILABLE SECTION DUCTILITY CAPACITY}

Several definitions for the available section ductility capacity and the associated maximum available curvature, $\phi_{u}$, have been considered in this investigation. The different available section capacities considered are: a) Fracture of the longitudinal reinforcement; b) Loss of confinement due to fracture of the transverse reinforcement; c) Important reduction of the load carrying capacity, and d) Buckling of longitudinal reinforcement.

a) Fracture of transverse reinforcement Experimental research conducted at the University of Canterbury with specimens under compression and confined by transverse reinforcement [7] indicate that the maximum concrete compression strain before fracture of hoops is

$\epsilon_{\mathrm{cm}}=0.004+0.090 \rho_{\mathrm{s}} \mathrm{f}_{\mathrm{yh}} / 300$

in which $f_{y h}=$ hoop steel yield strength (MPa), and $\rho_{s}=$ ratio of volume of transverse hoops to volume of concrete core. For column sections having a strain gradient, very little experimental data is available [7]. These results indicate that using Equation 11 in such cases is very conservative, and a better approximation to the maximum concrete compression strain related to the fracture of hoops is given by $3 \epsilon_{\mathrm{cm}}$, which was the value selected in this investigation for this failure mode.

b) Reduction of load carrying capacity some investigators [2] suggest that the maximum available ultimate curvature is obtained when the load carrying capacity has a 20 percent drop. A similar approach is followed in this investigation but using a more conservative value of 15 percent drop. 
TABLE 1

PROPERTIES OF MEXICO MANUFACTURED STEEL REINFORCING BARS

\begin{tabular}{|c|c|c|c|}
\hline \multirow{2}{*}{} & \multicolumn{3}{|c|}{ STEEL TYPE } \\
\cline { 2 - 4 } & $\mathrm{A} 1$ & $\mathrm{~A} 2$ & $\mathrm{~A} 3$ \\
\hline$\dot{\mathrm{f}}_{\mathrm{y}}(\mathrm{MPa})$ & 420 & 510 & 420 \\
$\mathrm{f}_{\mathrm{su}}(\mathrm{MPa})$ & 720 & 1200 & 630 \\
$\epsilon_{\mathrm{y}}$ & 0.002 & 0.0025 & 0.002 \\
$\epsilon_{\mathrm{sh}}$ & 0.010 & 0.010 & 0.010 \\
$\epsilon_{\mathrm{su}}$ & 0.130 & 0.180 & 0.080 \\
\hline
\end{tabular}
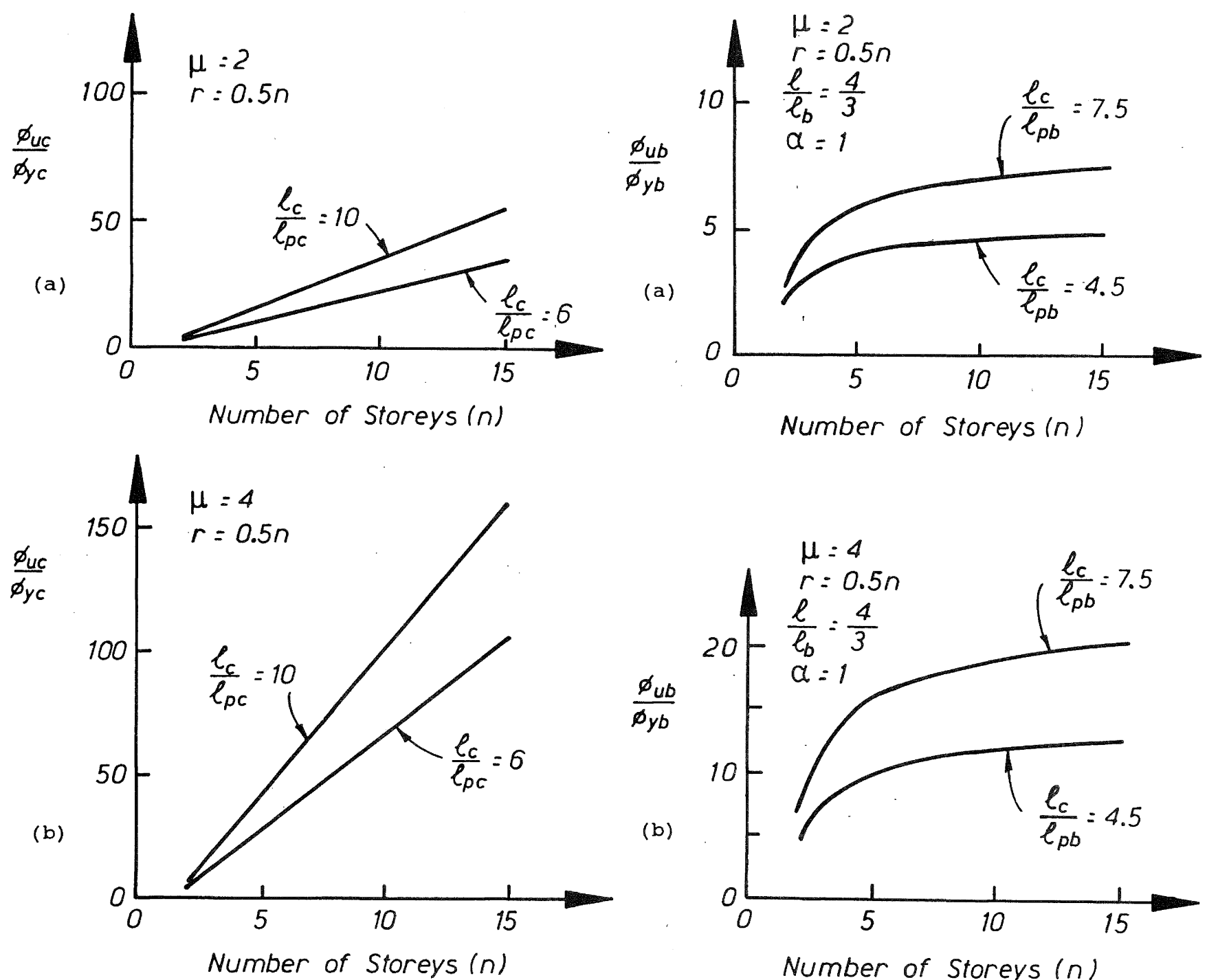

Figure 2 Ductility demands in column sidesway mechanism

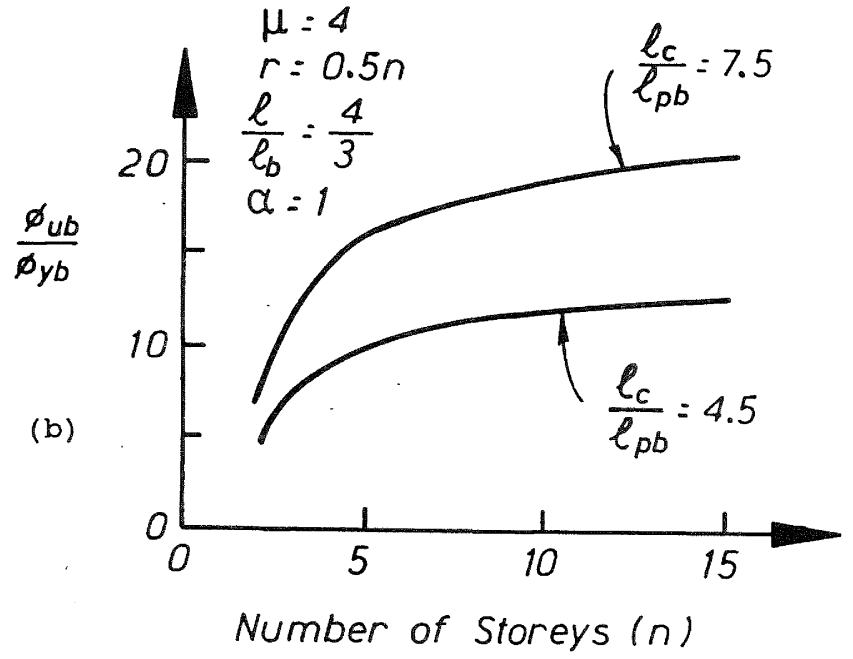

a) Displacement ductility equal to two

b) Displacement ductility equal to

Figure 3 Ductility demands in beams for the beam sidesway mechanism

a) Ductility displacement equal to two

b) Ductility displacement equal to four 

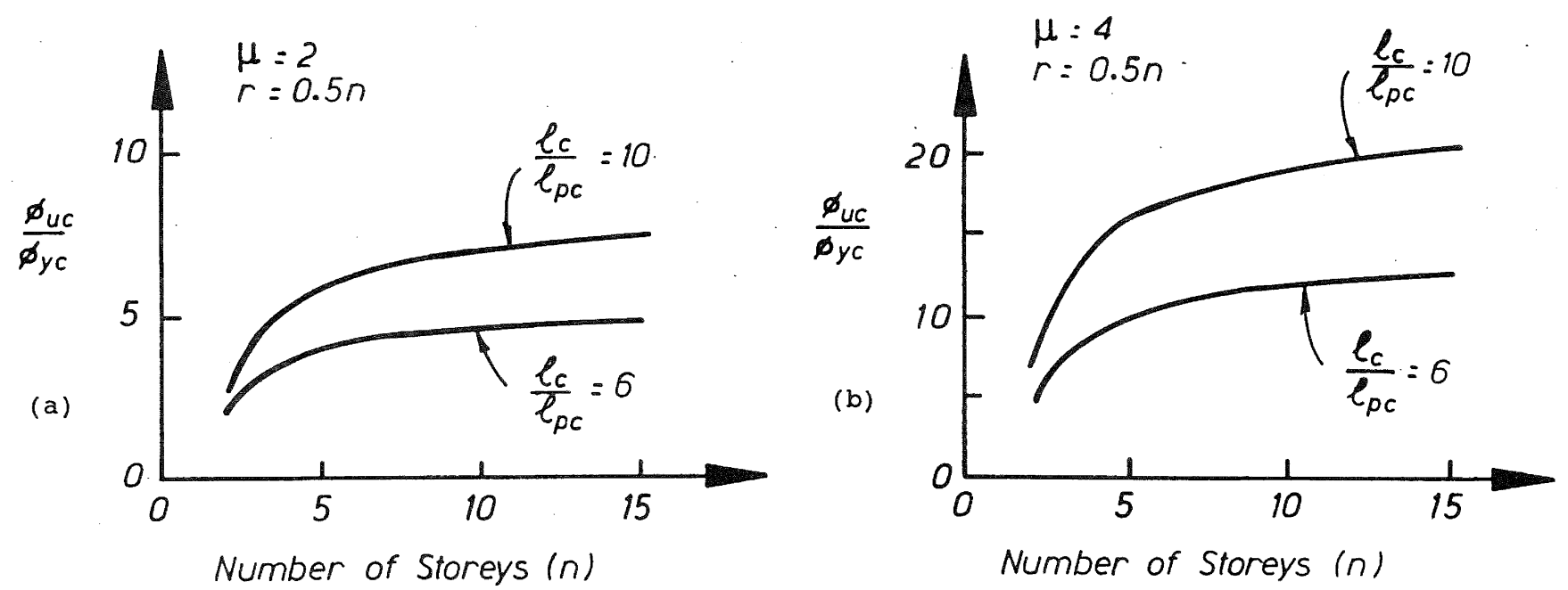

Figure 4 Ductility demands in column bases for the beam sidesway mechanism

a) Ductility displacement equal to two

b) Ductility displacement equal to four

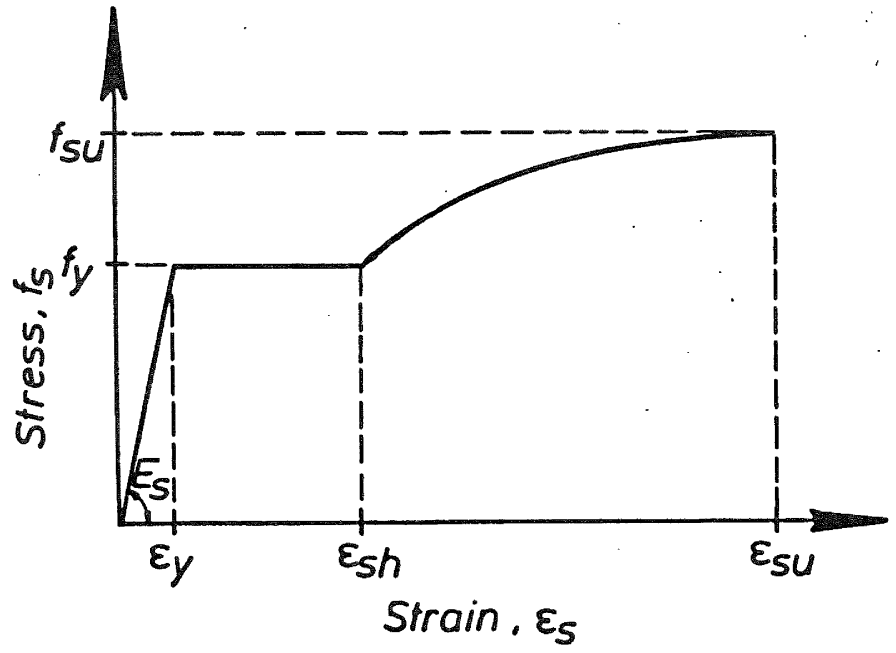

Figure 5 Monotonic stress-strain curve for steel reinforcement

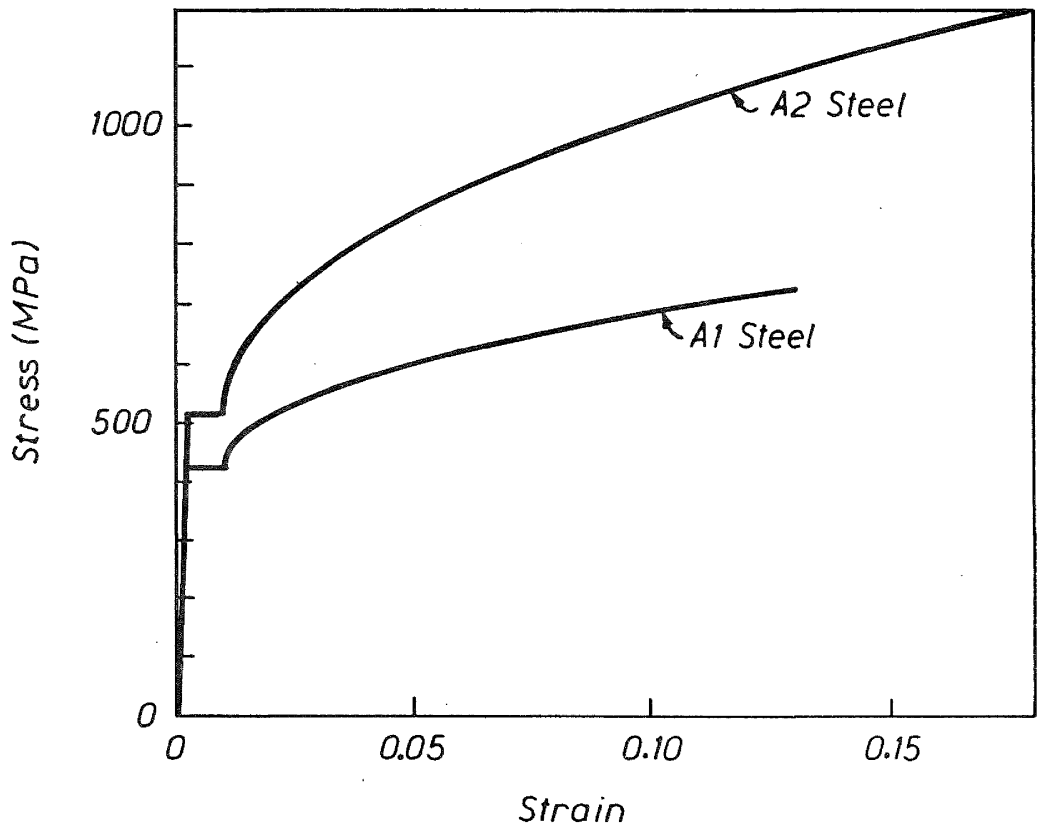

Figure 6 stress-strain cur'es for reinforcing steel 
C) Buckling of longitudinal reinforcement Building codes in seismic areas require hoops not only for providing member shear capacity and confining the compressed concrete but also for preventing the buckling of longitudinal reinforcement. This type of failure has been observed in experimental research $[2,12]$ and structural damage surveys after strong earthquakes [15]. Because the exact analytical formulation of the problem is complex, a simplifying approach was assumed here to model the buckling problem. In this model the longitudinal bar is restrained laterally at a length equal to the hoop spacing, $s_{h}$, which also defines the critical buckling length. The mathematical model of the buckling problem for stresses larger than the yielding stress is based in the column buckling analogy $[8,9]$ using the theory of the reduced modulus [8]. According to this theory the critical buckling stress, $f_{p}$, for a bar with diameter $D$ can be defined as

$$
f_{p}=\frac{\pi^{2}}{16} \frac{E_{r}}{\left(s_{h} / D\right)^{2}}
$$

in which $E_{r}$ is the reduced modulus of the reinforcing bar. Because $E_{r}$ must correspond with $f_{p}$, the solution of Equation 12 must be based on an iterative procedure using the stress-strain diagram of the reinforcing bar. Following a procedure outlined by Bernal
[10], the solution of Equation 12 was obtained [11]. Typical results in terms of the ratio $s_{h} / D$ are shown in Figure 7 for both the buckling stress and the corresponding steel strain.

In the elastic range of the steel reinforcement and depending mainly on the ratio $s_{h} / D$ and the type of steel, the loss of concrete cover may cause the buckling of the reinforcing bars. Examples of this type of buckling have been observed in experimental research with columns having Grade 280 reinforcing bars with $s_{h} / D$ ratios of about 10 [12]. Based on this evidence, the author has conservatively assumed that loss of concrete cover occurs at a maximum concrete compressive strain of 0.004 , and buckling of reinforcing bars will occur for ratios $s_{h} / D$ greater than those corresponding to the yield stresses shown in Figure 7 .

\section{TYPICAL REINFORCED CONCRETE FRAMES DESIGNED ACCORDING TO SEISMIC CODE PROVISIONS FOR MEXICO CITY}

Three typical moment-resistant frame buildings designed according to different Mexico City Seismic Code provisions were studied in this investigation. One is an existing building affected by the 1985 Mexico Earthquake and the other two are hypothetical buildings.

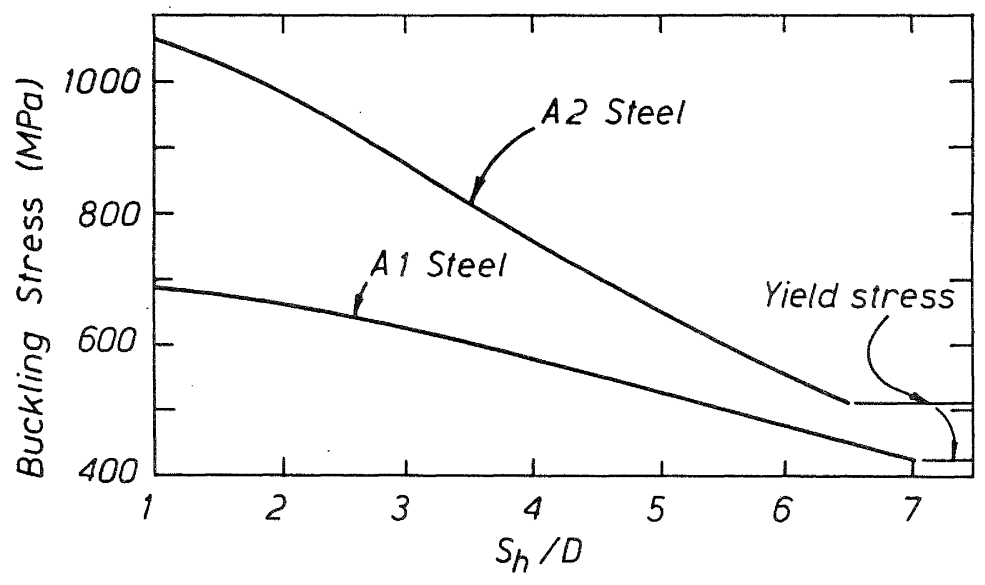

(b)

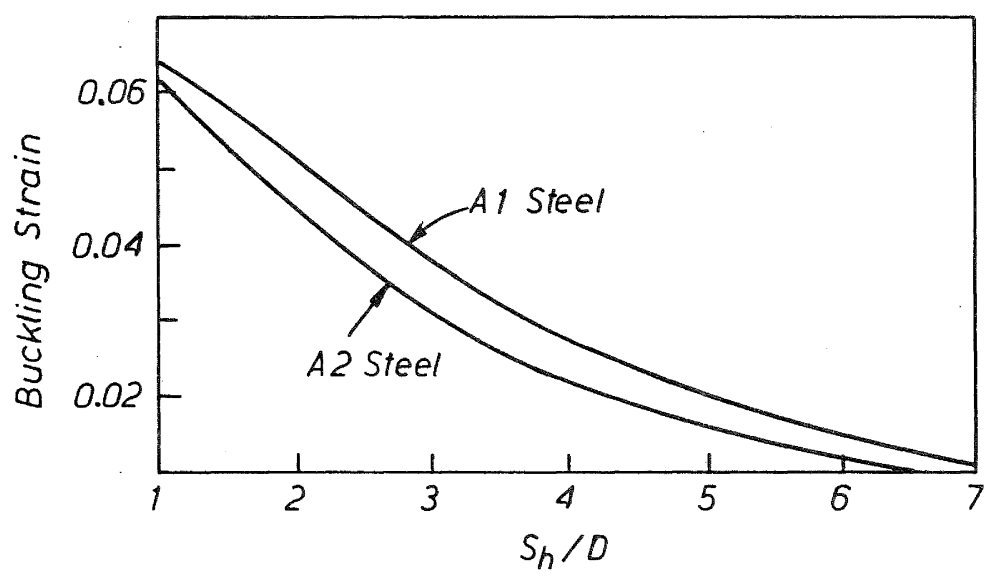

Figure 7 Inelastic buckling of reinforcing bars a) Buckling stress b) Buckling strain 


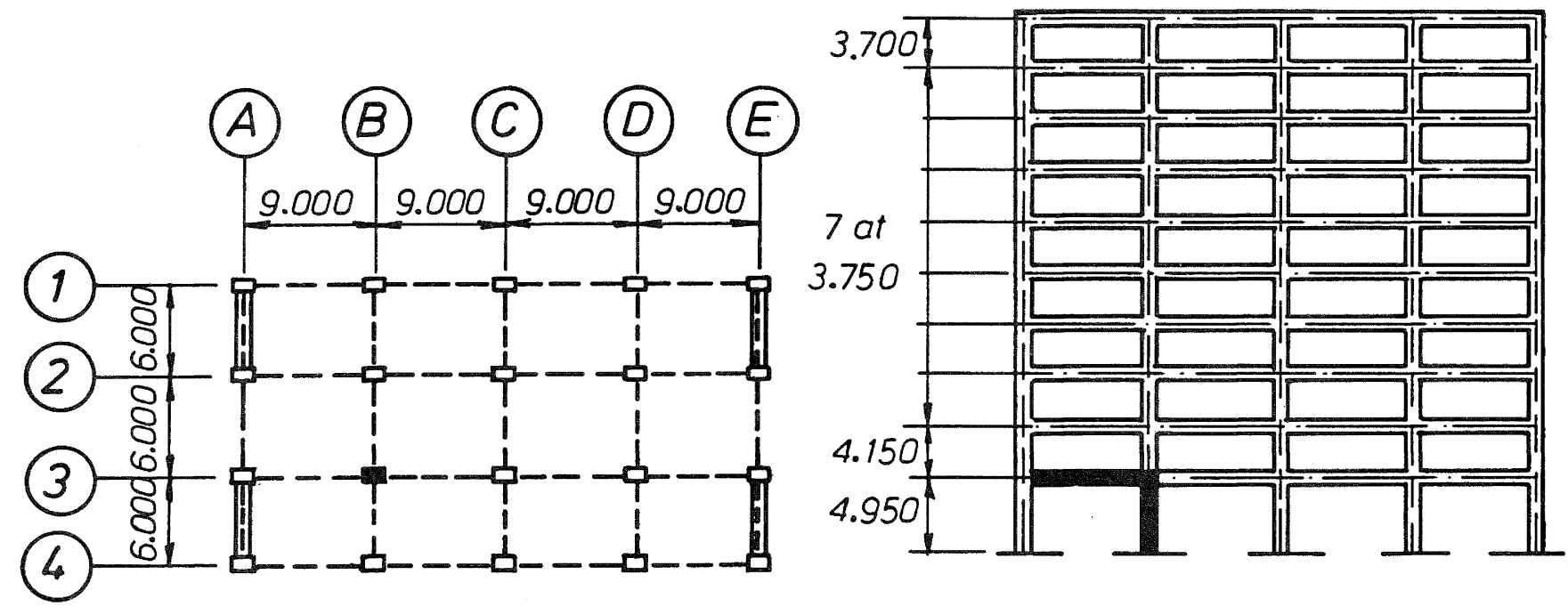

(a) PLAN

(b) ELEVATION OF TYPICAL FRAME ( $A X / S$ 3)

Figure 8 Plan and elevation of the STC building

a) Plan

b) Elevation

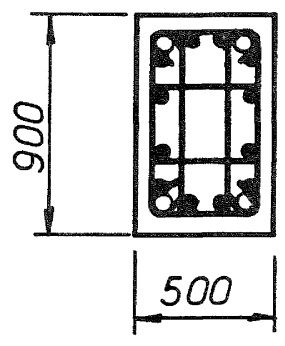

- $H D 32$

$\circ H D 38$

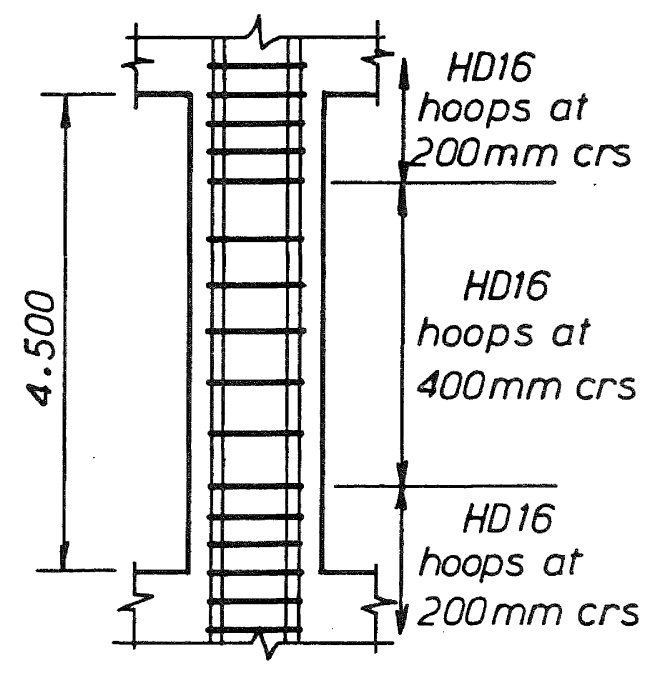

(a) COLUMN STC

Figure 9 Reinforcement details of typical members in the STC building

a) Column STC

b) Beam STC

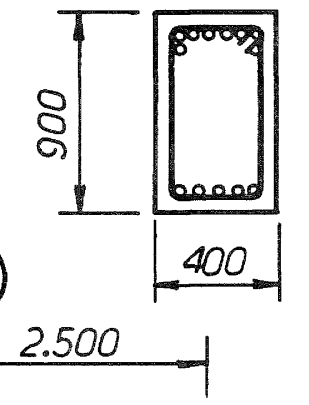

(A)

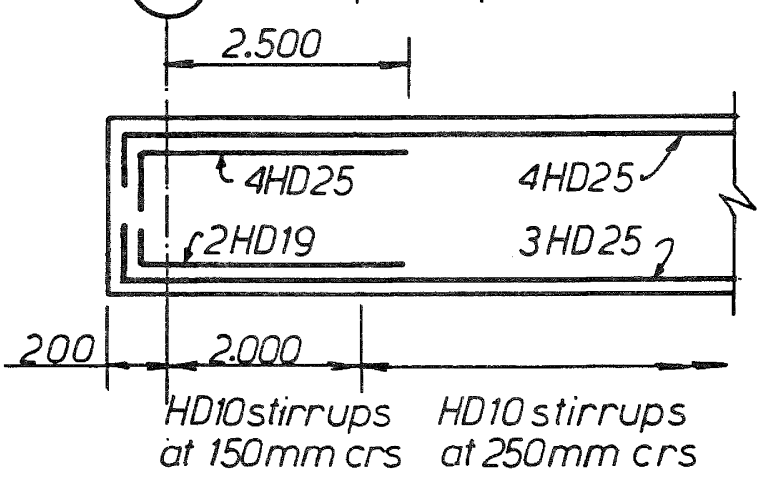

(b) BEAM STC 


\section{Description of the buildings.}

\section{STC Building}

This is a 10 storey reinforced concrete building designed according to the 1966 seismic code provisions for Mexico City [14]. The structural system is based on moment resistant frames in the longitudinal direction and in combination with shear walls in the transverse direction, Figure 8. The frame on line 3 in the longitudinal direction was selected for this study, referred to as the SCT frame. The 1985 Mexico Earthquake caused severe damage in the SCT building mainly in the longitudinal direction. The damage evaluation clearly indicated the formation of plastic hinges at beams in the lower stories and at the base of the columns, in both cases with buckling of the longitudinal bars [15]. Dimensions and reinforcement details of representative structural members in the first level of the SCT frame are illustrated in Figure 9. These members are an interior column, and an edge beam as shown in Figure 8 .

Buildings designed according to the 1976 and 1987 Mexico Codes.

The 1976 seismic provisions for Mexico City [16], and the current seismic provisions for Mexico City [3] were used for designing two fully ductile moment-resistant frame buildings. Dimensions of these buildings are shown in Figure 10. One typical interior frame from each of these buildings was selected in this study. In the following, the frame corresponding to the 1976 Mexico City code is referred to as the F76 frame. The one corresponding to the 1987 Mexico City code is referred to as the F87 frame. Dimensions and reinforcement details of representative structural members in the first level of these frames are illustrated in Figure 11. In both cases an edge column and an edge beam were selected for this study (See Figure 10).

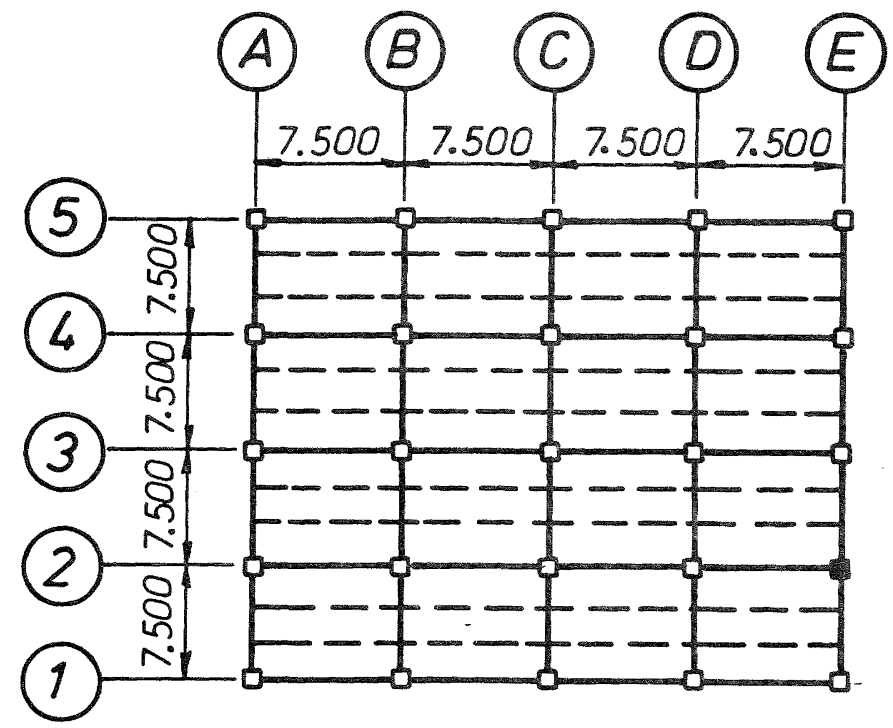

(a) PLAN
ANALYSIS OF THE DUCTILITY CAPACITIES IN THE FRAMES STUDIED

\section{Curvature ductility capacity}

Experimental testing and moment-curvature analysis of columns do not show a welldefined yield point in the force-deformation relationship. A definition of yield point for these cases, and used in this investigation, is suggested by Park [17], and illustrated in Figure 12. This definition relates the yield point to the yield deformation of the equivalent elasto-plastic system with reduced stiffness found at the secant stiffness at $75 \%$ of the ultimate lateral strength. In the cases of beams, a different approach was used. The results found in this investigation suggest that in most cases force-deformation relations can be defined by an ideal bilinear behaviour with positive post-elastic slope.

Moment-curvature analyses were used to evaluate the strength and maximum available curvature ductility of typical structural sections of members of the three selected frames. The stress-strain curve for the confined concrete section was based in the modified Kent and Park model [13], and only monotonic behaviour was considered for the reinforcing steel, using the stress-strain curves shown in Figure 6 .

Typical results of moment-curvature analyses of several column sections performed in this investigation are shown in Figure 13, where A1 and A2 identify the steel type. Curvature ductility ratios found for column sections of the STC and F76 frames ranged from 4 to 6 , whereas for the F87 frame this ratio ranged from 13 to 22 depending on the type of steel. As can be seen in Figure 13, in columns of the STC and F76 frames the maximum available curvature was governed by reduction of the load carrying capacity, although in some cases these curvatures were near those related to the buckling of longitudinal reinforcement. It was also found that because this steel had no significant incursions in

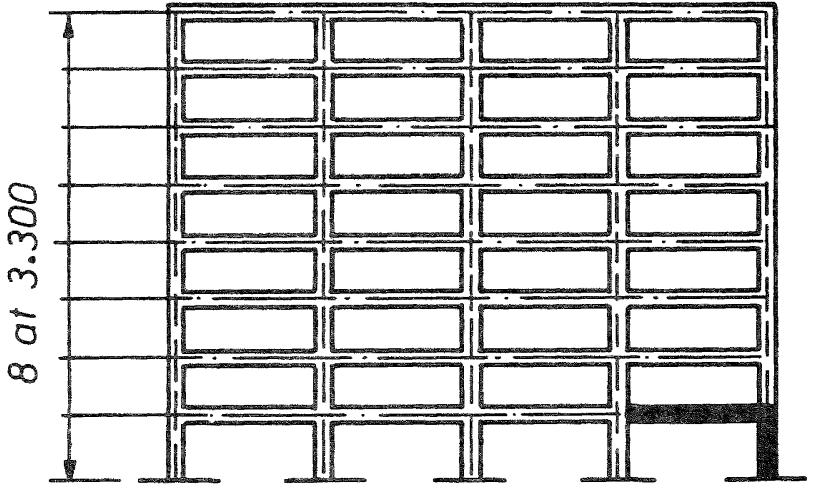

(b) ELEVATION OF TYPICAL FRAME (AXIS 2)

Figure 10 Plan and elevation of the 1976 and 1987 Mexican code designed buildings

a) Plan

b) Elevation 


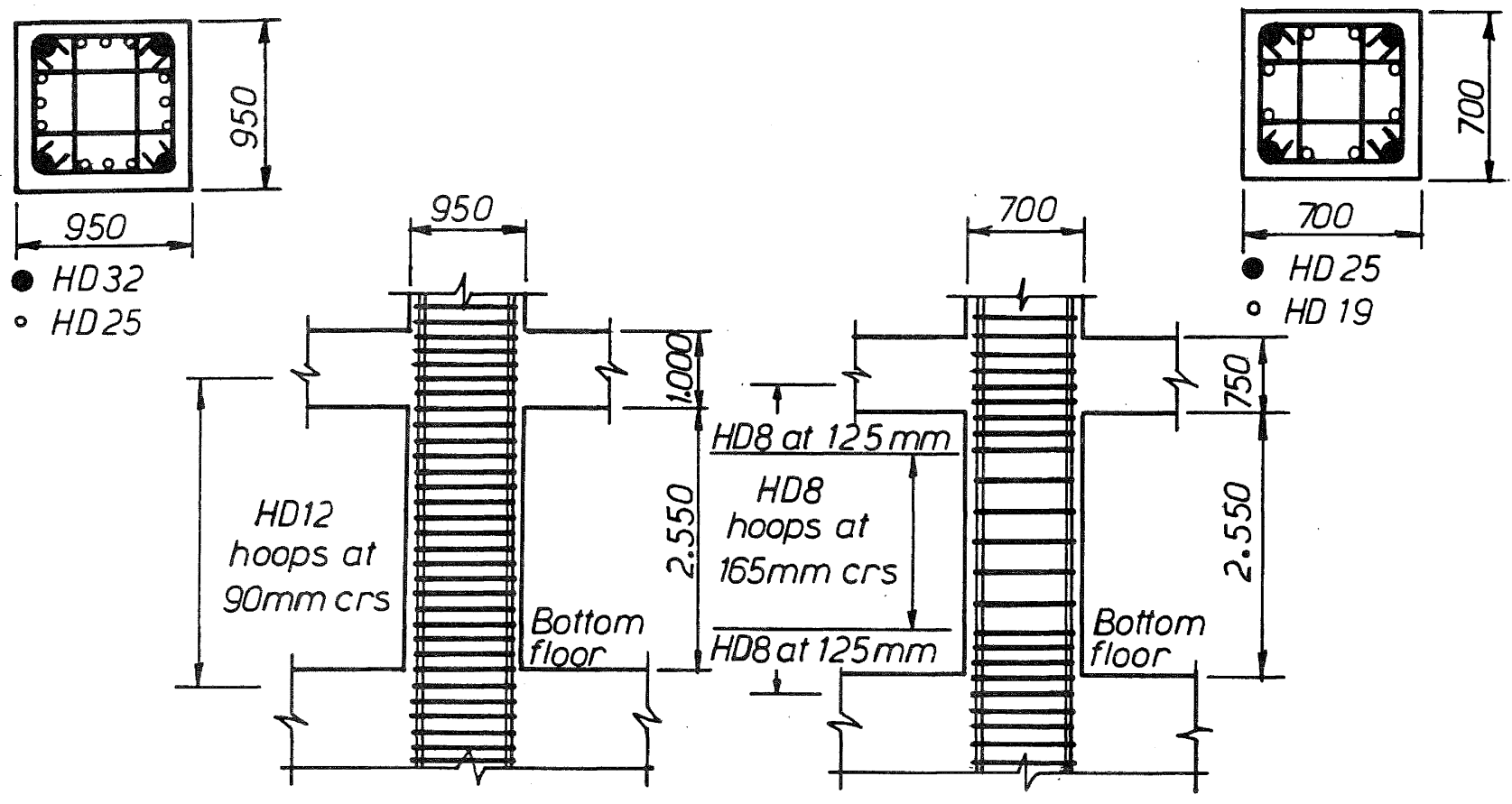

(a) COLUMNS
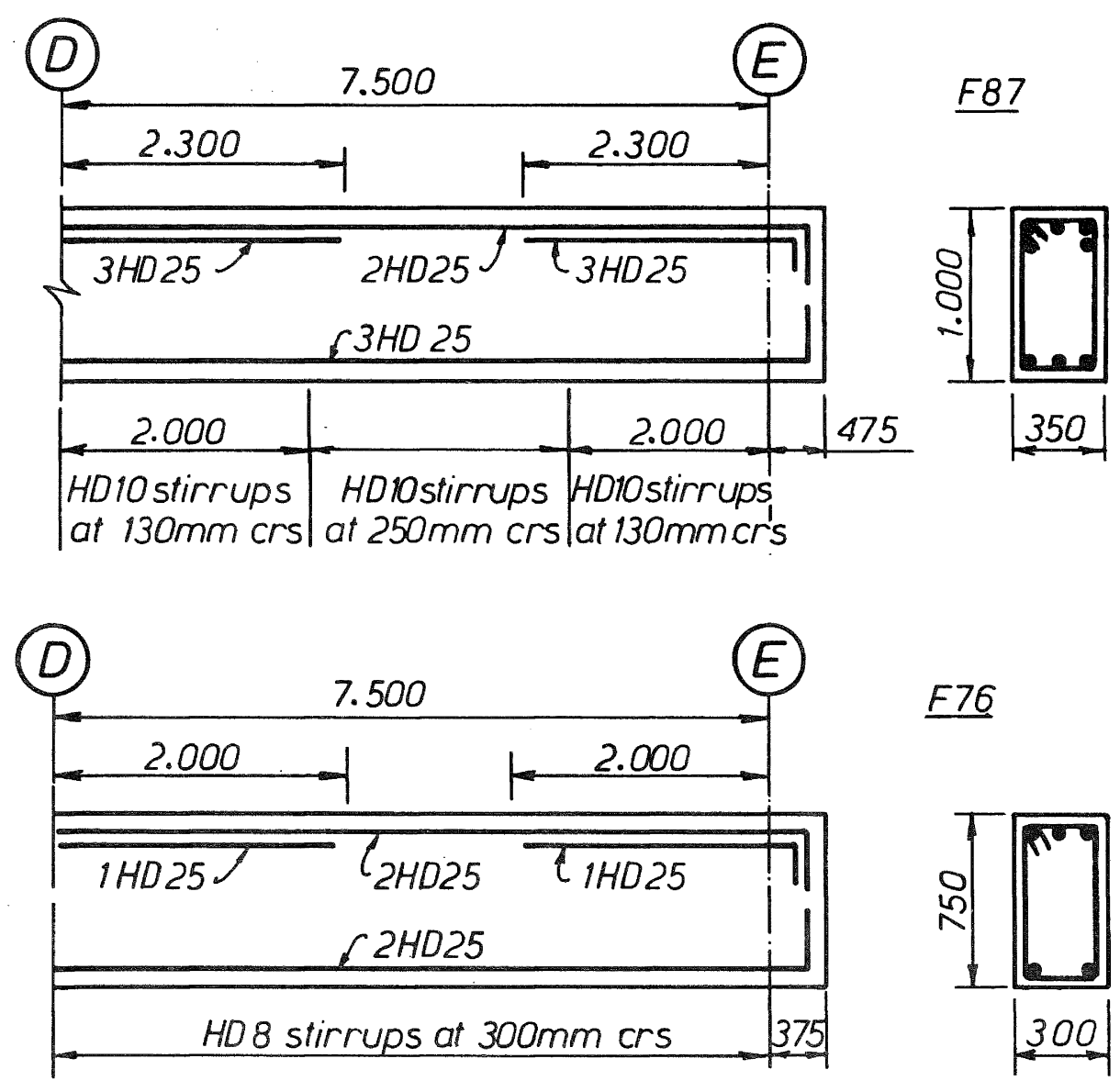

(b) BEAMS

Figure 11 Reinforcement details of typical members of the 1976 and 1987 Mexican code designed buildings

a) Columns

b) Beams 


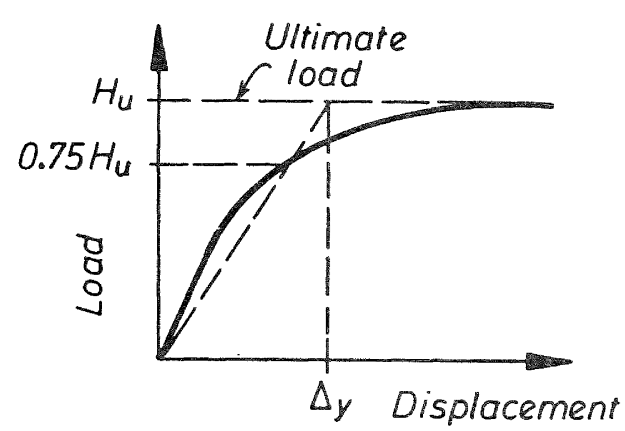

Figure 12 Definition of yield displacement [17]

the strain hardening zone, the type of steel was not important. This was not the case for columns of the F87 frame, Figure 13(c), in which the curvature ratio of the stronger steel, A2, was $50 \%$ less than the weaker steel, A1. This can be explained by considering that in these columns the maximum available curvature was governed by buckling of the longitudinal reinforcement, and as can be seen in Figure 7 , for a specific $S_{h} / D$ ratio an $A 2$ steel reinforcing bar buckles with a deformation smaller than that of an A1 steel reinforcing bar.

Results of moment-curvature analyses for some typical beam sections of the three frames studied are shown in Figure 14. In all cases the available curvature ductility ratios for beams in the three frames were governed by negative moment with buckling of the lower longitudinal steel, and as in the case of F87 frame columns, the A2 steel decreased the available curvature ratio by about $50 \%$ compared with the ratios obtained using the A1 steel. An example of this behaviour is shown in Figure 14 (c) corresponding to the F87 frame beam. Curvature ductility ratios found in beams of the STC and F76 frames ranged from 7 to 15, and for the F87 frame this ratio ranged from 15 to 30 .

Maximum Available Overall Displacement Ductility Ratio

Sidesway beam mechanisms were assumed for the different frames studied in this investigation. This assumption was based on reviewing the flexural strength of the members in the frames calculated from the moment-curvature analysis. In the case of the STC frame, the survey of damage in the STC building showed evidence of formation of this type of collapse mechanism [15]. Assuming this type of mechanism, and using the ratios of $1_{c} / 1_{p c}=10$ and $1_{c} / 1_{p h}=7.5$, based on the geometry of the STC and F76 frames, Figures 3 (a) and 4(a) show that to reach an overall displacement ductility ratio of two requires curvature ductility capacities in beams and columns of about 7. Although this demand is somewhat larger than the capacities found in the columns of these frames ( 4 to 6 ), because the method used to determine these demands is approximate, a ductility ratio of two can be considered as a reasonable approximation to the maximum available overall displacement ductility ratio.
Results of dynamic nonlinear analysis of the STC frame subjected to the 1985 SCT-EW earthquake record [15] indicate that maximum curvature ductility demands ranged from 10 to 20 in beams and from 7 to 14 in columns, using the plastic length 1.0 or 0.5 times the member depth respectively. This suggests that the methods used in this investigation might underestimate the structure ductility. However, because typical dynamic nonlinear analyses usually generate information on the envelopes of local ductility demands [20], it is not possible to infer values for the maximum overall displacement ductility ratio.

The $1_{c} / 1_{p c}$ and $1_{c} / 1_{p b}$ ratios for the F87 frame are about 6 and 4.5 respectively. Using these values and Figures $3(b)$ and $4(b)$ it can be seen that to reach an overall ductility displacement ratio of four, the curvature ductility ratio demand in beams and columns is approximately 12. The results from momentcurvature analyses previously discussed indicate that this can be easily achieved using $A 1$ steel in the F87 frame. However, Figures $13(\mathrm{c})$ and $14(\mathrm{c})$, with the strongest steel, A2, show that the curvature ductility capacity ranged from 13 to 15 , which is only slightly larger than the demand. This shows that the A2 type of steel should be used with caution, because of the low values of curvature ductility capacity associated with it.

\section{ANALYSIS OF THE FLEXURAL AND SHEAR CAPACITY}

Maximum moment capacities found in the moment-curvature analyses performed in this investigation were compared with the ACI [18] theoretical flexural strength using specified material strengths and a strength reduction factor $\phi=1$. Depending on the column section and type of steel, the overstrengths ranged from about $10 \%$ to $50 \%$ of the ACI value. Reasons for these differences are the conservative value of 0.003 assumed in the ACI for the extreme fibre concrete compression strain, the increase in the concrete compressive strength due to the confinement from hoops, and the increase in the longitudinal steel stress resulting from both the increase in the actual yield strength and strain hardening.

The moment-curvature analyses of beam sections indicated that strain hardening may cause flexural overstrengths significantly greater than that assumed by the ACI Code. Overstrengths of up to $80 \%$ and $180 \%$ of the $A C I$ value were found using $A 1$ and $A 2$ steel respectively.

The flexural overstrength in beams and columns can cause modes of failure not considered by designers, such as shear. The effect of flexural overstrength was studied assuming the structural member deformed in double curvature and with end resistant moments obtained from the moment-curvature analysis. The shear force obtained from this assumption was compared with the member shear strength according to the ACI code. In most of the cases the shear strength determined from the ACI code was greater than the shear determined from full flexural overstrength, indicating that these frames could develop plastic hinges. However, this was not the 


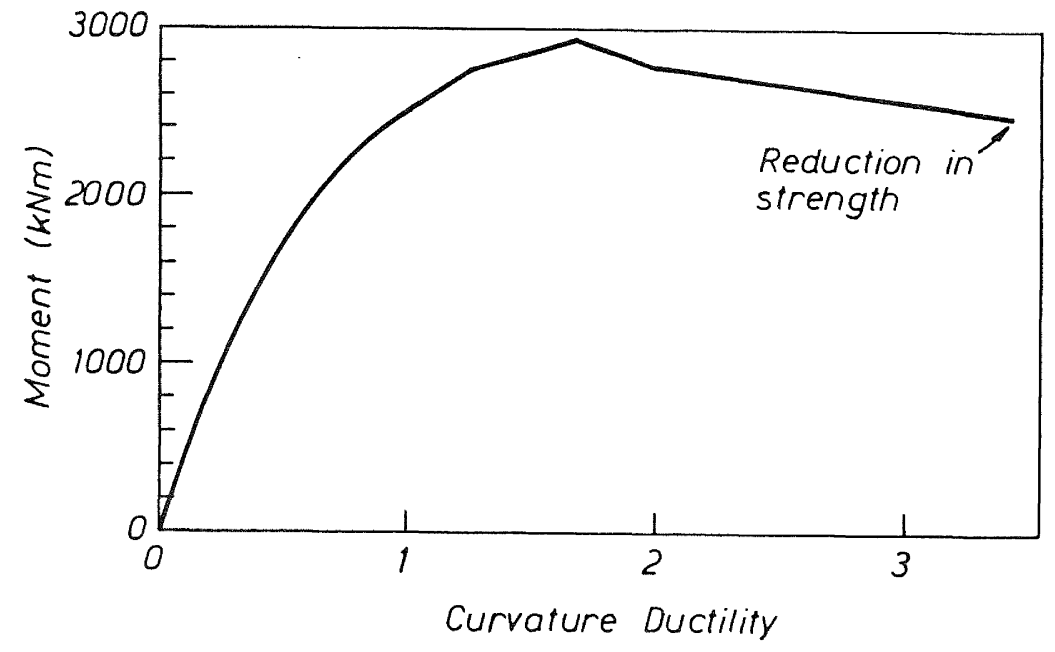

(a) COLUMN STC (AI STEEL)

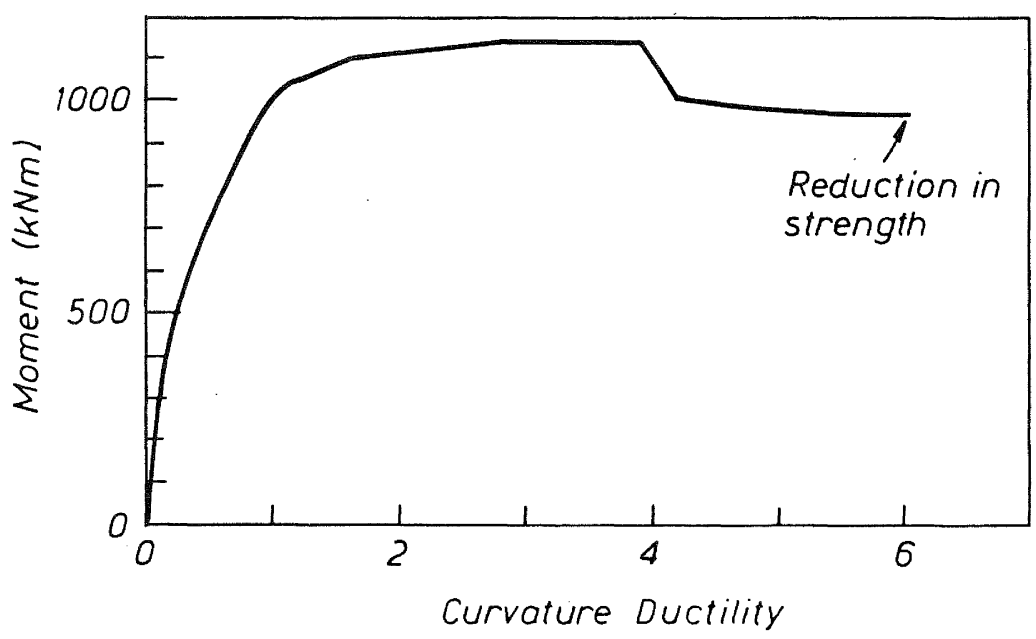

(b) COLUMN F76 (AISTEEL)

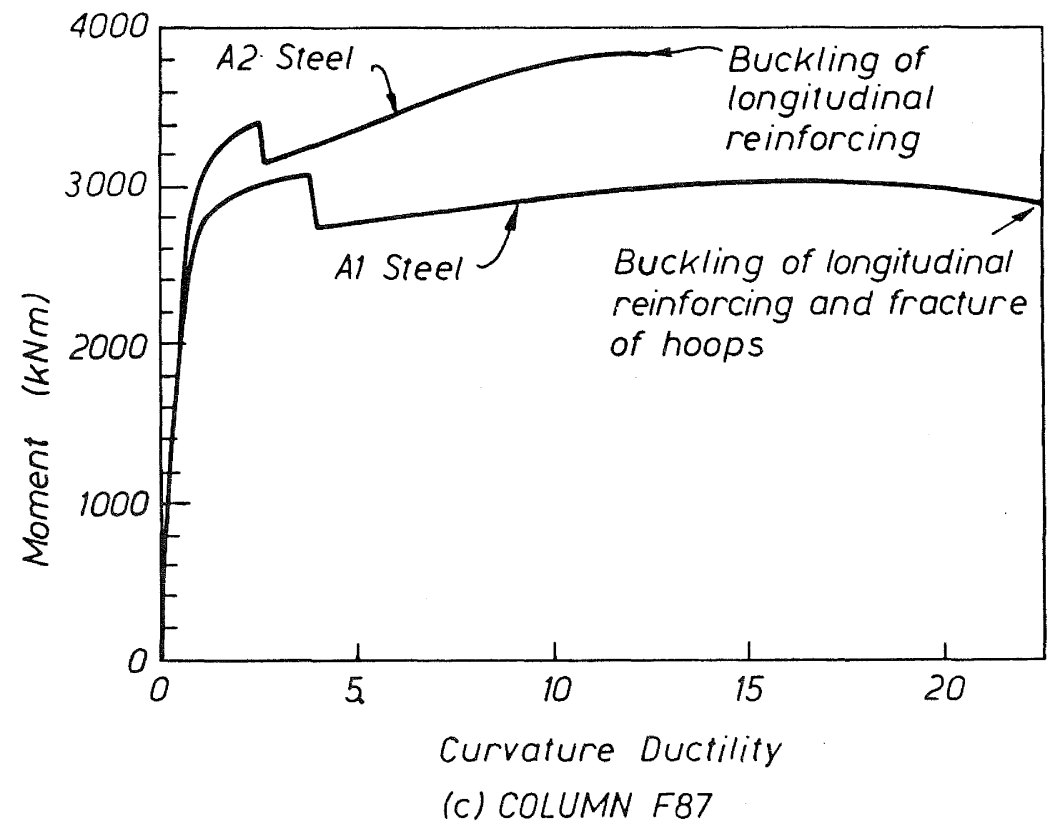

Figure 13 Moment-curvature analysis results of columns of the analysed buildings

a) Column STC (AI steel)

b) Column F76 (A1 Steel)

c) Column F87 

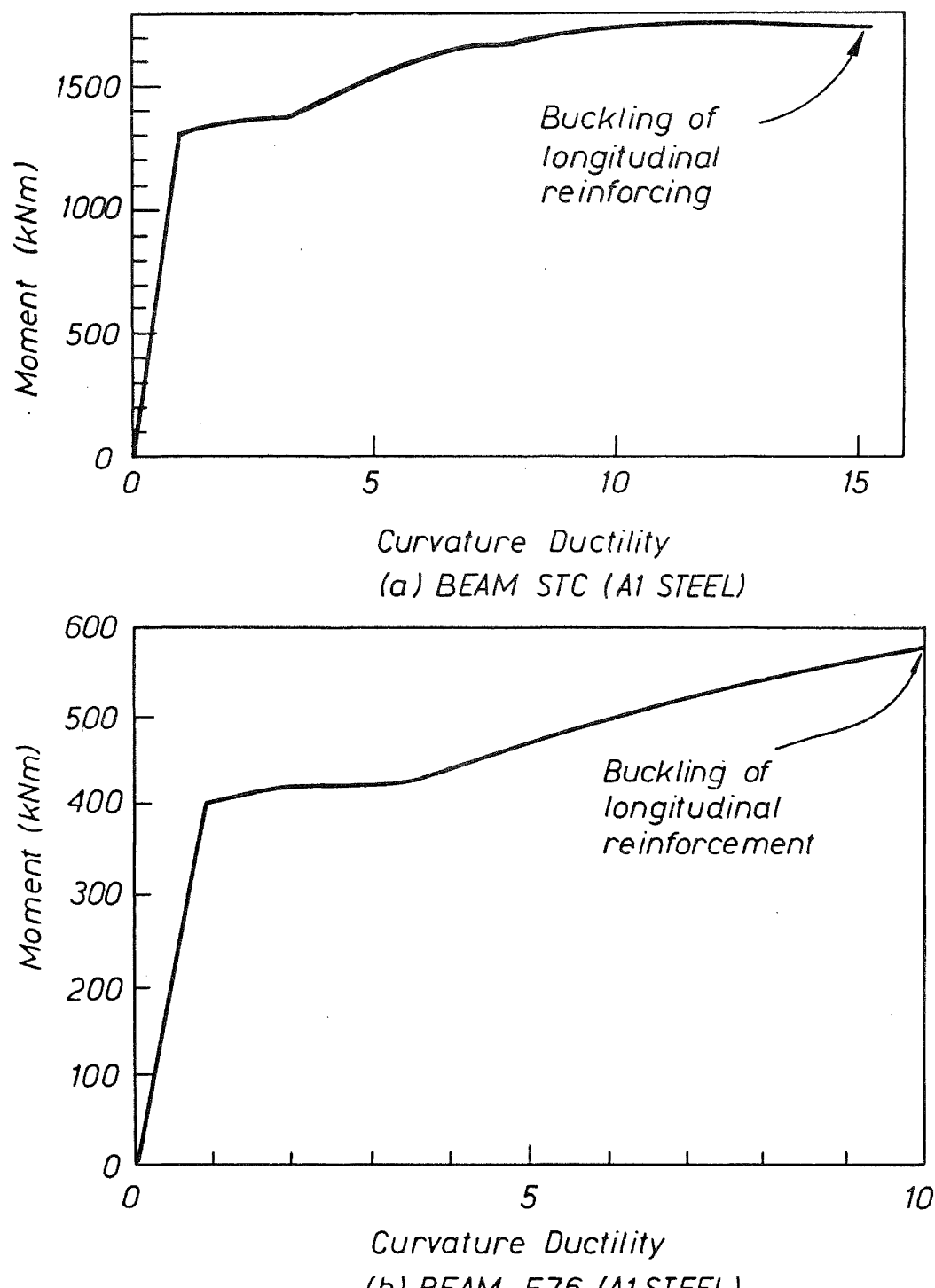

(b) BEAM F76 (A1STEEL)

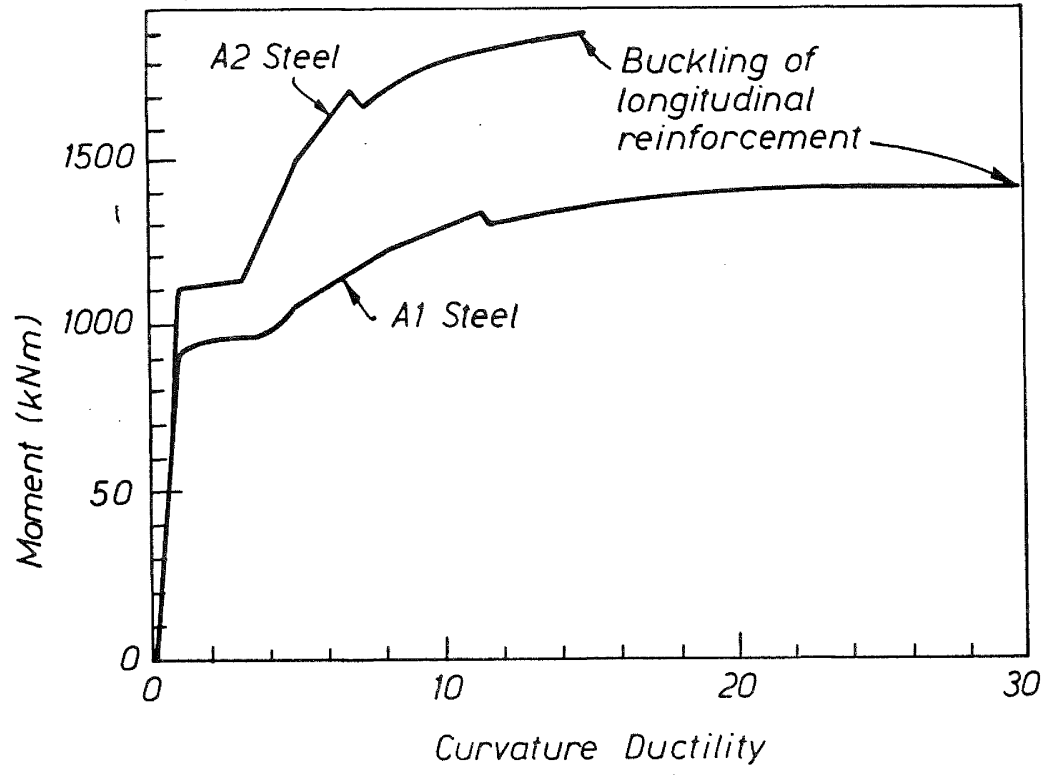

(c) BEAM F87

Figure 14 Moment-curvature analysis results of beams of the analysed buildings

a) Beam STC (AI Steel)

b) Beam F76 (A1 Steel)

c) Beam F87 
case for the F76 frame where the overstrength shear acting in beams and columns was larger than the calculated shear strength, by up to $30 \%$ and $50 \%$ with $\mathrm{A} 1$ and $\mathrm{A} 2$ steel respectively, indicating that shear failure would probably occur.

It is of interest that the New Zealand Standard for steel bar reinforcement [21] requires that the ratio of ultimate strength/yield strength of reinforcement not exceed either 1.4 or 1.5 , depending on the steel grade. Limitations to the range of steel strengths is also given in that standard.

\section{CONCLUSIONS}

1) Moment-curvature analyses were performed with typical structural sections of members in two RC frames designed as ductile frames according to building codes previous to the 1987 Mexico City Building Code. The results of these analyses and approximate expressions developed in this investigation for evaluating the global displacement ductility capacity of $R C$ frames indicate that these frames can develop a global displacement ductility factor of only about two. The same type of analysis performed with a structure designed as a fully ductile frame according to the 1987 Mexico City Building Code showed that the structural sections had significant increase in curvature ductility capacities compared with ductilities found in the frames previously mentioned; with these capacities a global displacement ductility of about four could be reached.

2) Results of this investigation show that columns of frames designed according to building codes previous to the 1987 Mexico City Building Code have significant strength degrading behaviour, with available curvature ductility ratios much lower than those found for the beams in these buildings. The ground motions recorded in Mexico City during the 19 September 1985 Mexico Earthquake indicate a significant number of yielding reversals with high ductility demands. These reversals caused greater strength degradation of columns, which explains the large number of failures of columns during this earthquake. on the other hand, column sections of a fully ductile RC frame designed according the 1987 Mexico City Building code did not show strength degrading behaviour, which indicates an improvement in fully ductile RC frames designed according to the current Building Code in Mexico City compared with structures designed according to previous codes in Mexico.

3) The moment-curvature analyses of beam sections performed in this investigation indicate that strain hardening of longitudinal reinforcement may cause significant flexural overstrength. However, in the case of columns this overstrength was not important. These overstrengths help to explain the differences found between the observed damage in RC frames caused by the 19 September 1985 Mexico Earthquake and results of analytical studies conducted with typical buildings affected by this earthquake [19]. It also gives additional reasons for explaining the large number of failures in columns compared with the number of failures in beams observed in this earthquake.

4) The overstrengths previously mentioned may lead to uneconomical design of structures. Furthermore, it may cause undesirable brittle shear failure modes rather than flexural mechanisms assumed in the original design. This investigation also indicates that high overstrengths resulting from excursions into the strain hardening region of the longitudinal reinforcement may cause significant reduction in curvature ductility capacity. In some cases this reduction was as great as $50 \%$ of the curvature ductility capacity obtained using reinforcing steel with less significant strain hardening. To avoid this reduction in ductility as well as uneconomical design of structures and brittle shear failures, it is suggested a stricter control be placed on the production of steel reinforcement in Mexico, aimed at reducing the ratio of ultimate strength to yield strength to the levels adopted by the New Zealand Standard [21].

\section{ACRNOWLEDGEMENTS}

This paper was prepared while the author was a Visiting Research Fellow in the Department of Civil Engineering of the University of Canterbury, Christchurch, New Zealand. The stay was possible by financial support from the Earthquake and War Damage Commission of New Zealand, the University of Canterbury, and the Instituto de Ingenieria, Universidad Nacional de Mexico. The author wants to acknowlewdge the contribution of Carlos Montoya, Graduate student in the Facultad de Ingenieria, Universidad Nacional de Mexico, for his assistance in the analytical studies performed in this investigation. Thanks are due to Professors Robert Park and Thomas Paulay, and Drs Nigel Cooke and Andrew Buchanan for their critical reading of the manuscript. The drawings of this paper were prepared by Mrs V Grey.

\section{REFERENCES}

1) Bertero, V.V., "Lessons Learned from Recent Earthquakes and Research and Implications for Earthquake-Resistant Design of Buildings structures in the United States", Earthquake Spectra Journal, Vol 2 (4), 1986

2) Priestley M.J.N. and Park R., "Strength and ductility of concrete Bridge Columns Under Seismic Loading", ACI Structural Journal, January-February 1987, pp 61-76.

3) "Mexico Code 1987", Reglamento de Construcciones para el DF, Diario oficial, Mexico, July 1987.

4) Park R. and Paulay T., "Reinforced Concrete structures", J. Wiley \& Sons , 1974 .

5) Corley G. "Rotational Capacity of Reinforced Concrete Beams" Journal of the Structural Division, ASCE, October 1966, pp 121-146. 
6) "Mexico Reinforcing steel Code 1987", Varillas corrugadas y lisas de acero, procedentes de lingote o palanquilla, para refuerzo de Concreto, NON B6, Direccion General de Normas, Secretaria de Comercio y Fomento Industrial, Mexico, 1987.

7) Scott B.D., Park R. and Priestley M.J.N., "Stress-Strain Behavior of Concrete Confined by Overlapping Hoops at Low and High strain Rates", ACI Journal, Proceedings Vol 79, No 1, Jan.-Feb. 1982, pp 13-27

8) Salmon c. and Johnson J., "Steel Structures", Second Edition, Harper and Row.

9) Bresler B. and Gilbert P.H., "The Requirements for Reinforced Concrete Columns",Journal of the American Concrete Institute, November 1961, pp 555-569

10) Bernal D." "Ductility and plastic rotations in critical sections of Reinforced Concrete Frames", Report Instituto de Ingenieria, UNAM, December 1982, (in spanish).

11) Montoya C. "Strength and Ductility of Reinforced Concrete Elements", Thesis, Facultad de Ingenieria, UNAM, January 1989, (in spanish).

12) Hudson F.,"Reinforced Concrete Columns:effects of lateral tie spacing on Ultimate strength", ACI Publication SP 13, 1966, pp 235-244

13) Park R.,Priestley M.J.N., and Gill W.D. , "Ductility of Square-Confined Concrete Columns," Proceedings, ASCE, V. 108, ST4, Apr. 1982, pp 929-950.

14) "Mexico Code 1966", Reglamento de Construcciones para el DF, Diario oficial, Mexico, 1966.

15) Meli R. and Avila J.," The Mexico Earthquake of September 19, 1985Analysis of Building Response", Earthquake Spectra Journal, Vol 5, Number 1, Feb. 1989, pp 1-16.

16) "Mexico Code 1976", Reglamento de Construcciones para el DF, Diario Oficial, December 151976.

17) Park R. "Ductility Evaluation From Laboratory and Analytical Testing", Proceedings of 9 th World Conference on Earthquake Engineering, Tokyo/Kyoto, (1988).

18) American Concrete Institute, "Building Code Requirements for Reinforced Concrete (ACI 318-83)", Detroit, Michigan

19) Meli R. and Avila J.," Analysis of Building Response of Some Buildings Damaged by the 19 September Mexico Earthquake" "Revista Ingenieria Sismica, Mexico, May-August 1989,pp 3552 , (in spanish).
20) Kanaan A. and Powell G. "DRAIN-2D, a general purpose computer program for dynamic analysis of inelastic plane structures." Report EERC 73-6 and EERC 73-22, University of California, Berkeley, California (1973)

21) "Steel Bars for the Reinforcement of Concrete" (NZS 3402:1989), Standards Association of New Zealand, Wellington. 